\title{
Design and Implementation of an Integrated Network Teaching Platform Based on SSH
}

\author{
Xiaochen Lai ${ }^{\mathrm{a}}$, Yangyang Shi ${ }^{\mathrm{b}}$, Zongzheng $\mathrm{Chi}^{\mathrm{c}}$ and Wanyue Cao ${ }^{\mathrm{d}}$ \\ Dalian University of Technology, China

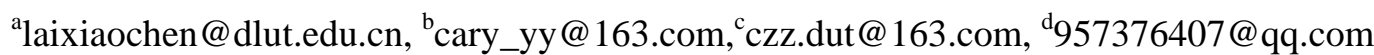

Keywords: SSH Framework, Teaching Platform, Homework Mark, Paper Format Check

\begin{abstract}
The teaching work of colleges and universities is diverse and laborious. In this paper, we design and implement an integrated network teaching platform consisting of five modules: course management, project management, announcement management, homework mark and paper format check. The course management module provides online presentation and video. The project management module allows students to query the research projects of teachers and sign up for what they are interested in. The announcement management module will promptly notify the teachers and students of the latest news. The homework mark module implements the homework online submission, online mark and online grade, etc. The format check module can check the papers' format of students and output error reports. The platform has the advantages of strong stability and scalability. It can greatly improve the efficiency of teachers and students.
\end{abstract}

\section{Introduction}

In the Internet ${ }^{+}$era, how to use Internet technology to serve for education is an important issue for the majority of educators[1]. Since 1990s, many schools have begun to promote the teaching network and it is a revolution of the cause of education [2]. However, many teachers and students are still accustomed to traditional teaching methods due to the late popularity of teaching network. The traditional education is a real-time and face-to-face teaching model with time and space limitations. It is extremely inconvenient for students of different regions. While modern teaching platform is based on Internet technology, teaching and learning will be integrated into online. Students and teachers located in all corners of the country can learn and teach on the same platform [3].

In the field of network teaching, foreign countries have invested a large amount of money in building teaching network. Many colleges and companies in the USA and the UK have joined the embrace of Internet education, providing online education and remote classroom. The network teaching has become an indispensable part of education.

Our government also attaches great importance to network teaching. Many colleges have invested much money in establishing a campus network platform to carry out network teaching. However, due to the late start of network education, there are still many deficiencies in information sharing and interaction [4]. The network education in developed countries has been leading for a long time and they have built a huge teaching resource library. While the ecological environment of teaching system in our country is not perfect enough, students and teachers do not have the awareness to communicate on the network platform.

In this paper, we design a comprehensive network teaching platform based on SSH framework [5]. It integrates the teaching information and two extended functions which are homework mark and paper format check. Teachers can complete most of the teaching work on this platform because it collects a great deal of teaching resource. At the same time, the two extended modules can effectively save the labor cost, which will place the cumbersome work to computer. The platform can greatly stimulate students' enthusiasm for learning and improve the efficiency of learning. 


\section{System design}

The system uses a three-layer architecture (browser / server / database server). Development tools is IntelliJ IDEA. The programming language is JSP. Database is MySQL5.7.Web container is Tomcat8, and the operating system is Win10.

System overall architecture design. The system is a Java Web application based on Strtuts2, Spring and Hibernate. The architecture is divided into three layers: presentation layer, business logic layer and data persistence layer[6]. Struts2 acts as a filter for the initialization of the configuration file to automatically load the Bean in the configuration file [7].Hibernate provides a relational database mapping to the entity class and the database operation interface [8]. Spring is responsible for the process of the business logic layer and provides the Service class with transaction management. The architecture separates the page display code and the logic code to meet the principles of high cohesion and low coupling. It enhances the readability of the system and reduce the complexity of the development and maintenance. The architecture of the system is as shown in Fig. 2.

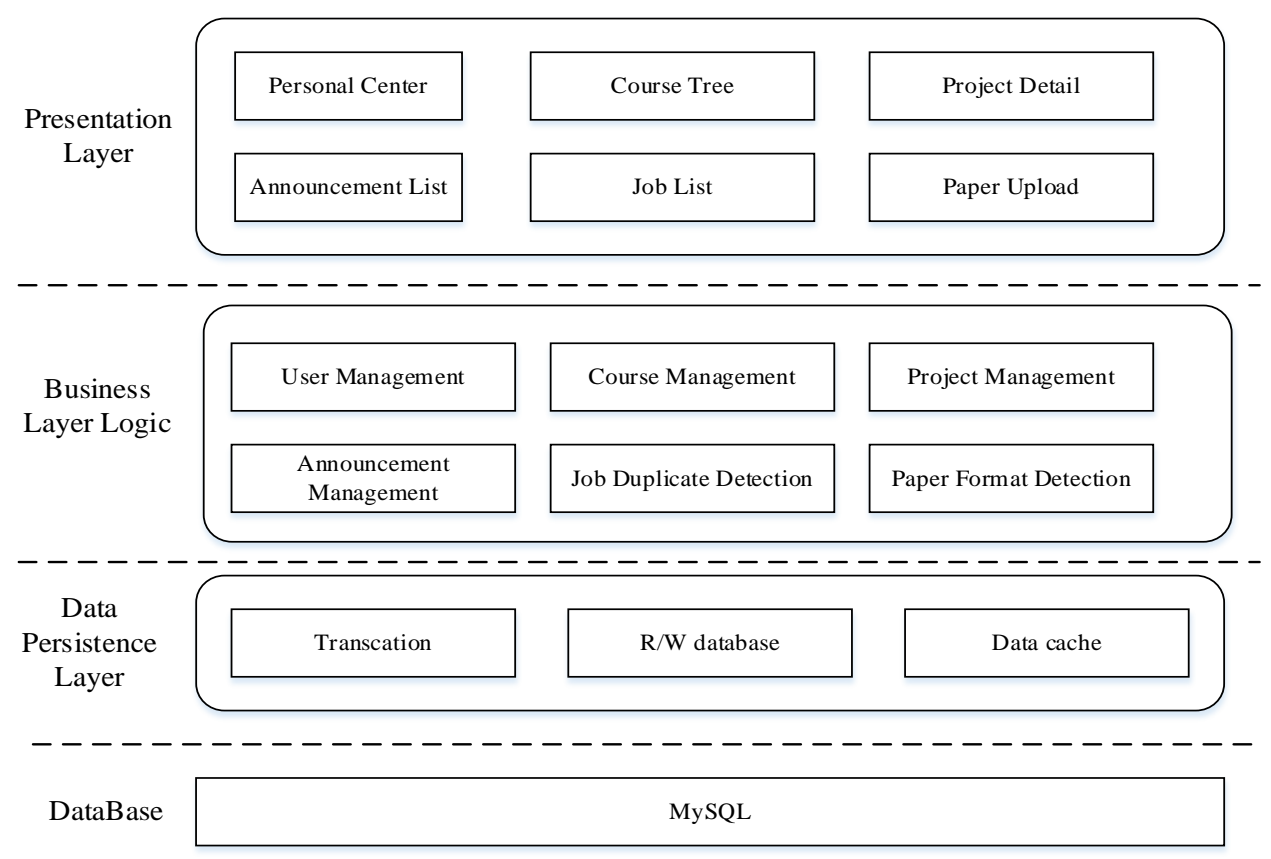

Fig. 1 System architecture

Functional Module division. The system contains seven functional modules, described as follows:

User management. This module is the basic and entrance of our system, including four basic functions: user registration, user login, user logout and user profile management.

Authority management. This module is set for the operation limitations of different users. The administrator has the highest authority; teachers have the authority of curriculum management, project management, announcement management, homework mark and paper format check; students only can modify their personal information.

Course management. In this module, teachers can add new courses and delete the uploaded courseware, while students only can watch and download them.

Project management. This module is mainly used to show the innovation and entrepreneurship projects of teachers. Students can take part in the projects they are interested in and teachers can add a new project, modify the projects and delete the projects, etc.

Announcement management. In this module, teachers can publish announcements to all users, and the system will immediately notify all users. 
Homework mark. This is one of the features of our system. It can do automatic compilation, automatic mark, program duplicate check and score.

Paper format checking. This is another feature of our system. It can check the format of the uploaded paper and output error report.

Database design.The database is the core of the Web application, and the functionality and performance of the Web application is largely dependent uponit.According to demand analysis, we designed the required database[9]. Let's take the structure of the teacher's table as example. We will introduce the structure of the database according to the E-R diagram of teachers as shown in Fig. 2.

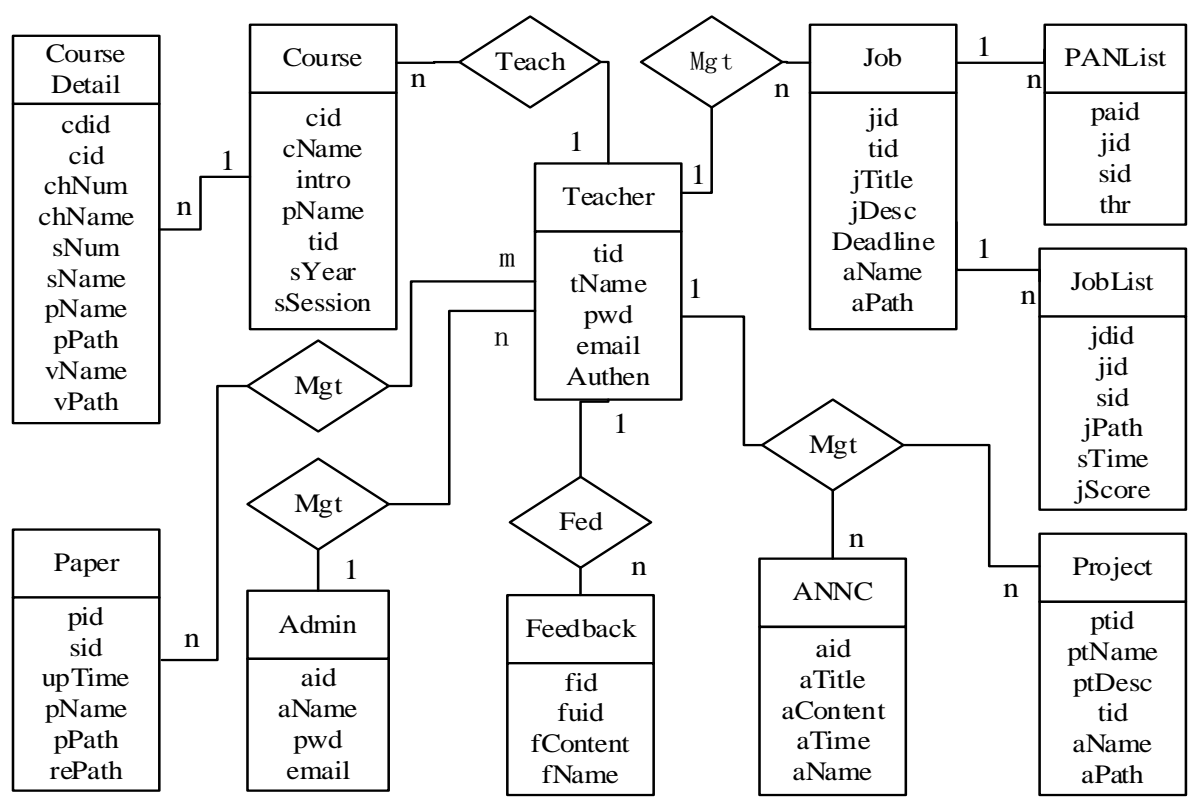

Fig. 2Teacher’s E-R diagram

The database in this module involves multiple tables, such as user table, curriculum table, project information table, announcement table, paper information table and feedback table, etc. We need to consider the constraints among these tables carefully before designing the database because it is the foundation of the properly running of our system. Table 1 is the paper information table and other tables are omitted.

Table1Paper Format Check table

\begin{tabular}{ccccc}
\hline Column & Interpretation & Type & $\begin{array}{c}\text { Primary } \\
\text { Key }\end{array}$ & NULL \\
\hline ID & Paper number & $\operatorname{int}(11)$ & Yse & No \\
sID & Student ID & $\operatorname{char(9)}$ & Yse & No \\
name & Student name & $\operatorname{varchar(20)}$ & No & No \\
ptime & Check time & date & No & No \\
pName & Paper name & $\operatorname{varchar(50)}$ & No & No \\
pPath & Papaer path & $\operatorname{varchar}(50)$ & No & No \\
rPath & Report path & $\operatorname{varchar}(50)$ & No & Yes \\
\hline
\end{tabular}

ID is the primary key of the table; ptime is the time when students upload papers; pName and pPath are names and paths of the uploaded papers. Finally, the report path is stored in the rPath after the examining report is generated. 


\section{Design and implementation of main functional modules}

We will take homework mark and paper format check module as example to introduce the design mthod of the functional modules.

Homework mark. Itis a vital featureofour system. It is divided into three sub-modules, including automatic compilation, automatic mark and homework duplicate check.The system will execute these modules in turn after the due date. After the student submits his homework, our system will automatically compile and generate the executable file, and then obtain the base score according to the test case. Finally, it calls the local duplicate check program to checkplagiarism and save the result to the database. It can greatly reduce the workload of teachers. However, this system onlychecks $\mathrm{C} / \mathrm{Cpp}$ programspresently.We will continue to improve itscompatibility. The work flow of this module is shown in Fig. 3.
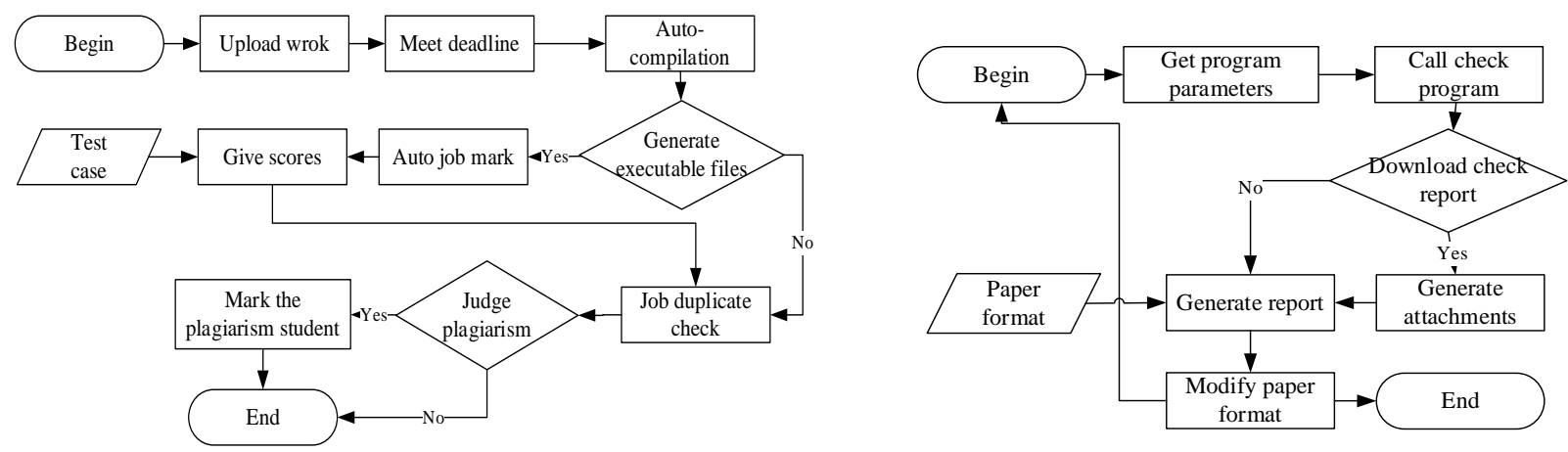

Fig. 3 Homework mark flowchart

Fig. 4Paperformatcheck flowchart

Timer trigger.The system will automatically poll the databasein 23:55 every day to find the records which meetthe due date. If the query results is not empty, it will call the next step. Our system uses Quartz technology to implementthe timing function[10], and it is powerful compared to the Timer of Java and lightweight timer function of Spring.

Automatic compilation.It is implemented in the main method of AutoCompile.java. The first parameter is the homework directory, the second parameter is the answer of this homework and the third parameter is the id of it. These parameters can be obtained from the database.

Automatic mark. After generating the executable file, the system will use the right answer to verify the correctness of the homework and determine the score of it based on the pass rate of the test case. Finally, the score will be stored in the database.

Duplicate check.Our system will call the dulpicate check program in this step.The homework will beidentified as plagiarismif the checking result is higherthan threshold andthe result will be stored in the file.

Paper format check. Itis another vital feature of our system, which implements the automatic check of papers' format. There are three types of papers supported by our system so far, including undergraduate papers, engineering papers and engineering thesis. First, users can choose the type of papers and upload it. Then, the system will store the student number, uploaded time, file path and the path of generated report into the database. Next, the system will use the path of the paper as parameter to invoke the local format check program, and output the difference between the uploaded paper and the template. Finally, users can view the error report and revise the format of their papers. The process of this module as shown in Fig. 4.

\section{System implementation}

The system has been put into use in our college for one year and the number of registered users has been over 1,000.The basic modules of our system, including user management, authority management, curriculum management, project management, announcement management modules 
all work well. For expansion modules of our system, homework mark and paper format check module, we set a feedback mechanism to collect the feedbacks of users. At present, we have marked more than 2,000 homework and checked more than 3,000 papers. The result of homework mark and paper format check have a high accuracy and the feedback is good.

\section{Conclusion}

The system, based on the SSH framework, realizes an integrated teaching platform which combines curriculum, project and announcement information. It meets the online teaching needs of teachers and students. In addition, homework mark and paper format check module are the features of our platform. It can greatly improve the efficiency of teachers and students. The function of each module has been achieved and the system has been put into use. There are still some flaws in the platform due to the security hole of the SSH framework.

\section{Acknowledgement}

This work is supported by the Teaching Reform Fund of Postgraduate of Dalian University of Technology under Grant Jg2017007, the Industry-Academy Cooperation Fund of Ministry of Education under Grants 201602007011, 201602015006 and 201601007002, and the Teaching Reform Fund of School of Distance and Continuing Education of Dalian University of Technology under Grant ZD201632.

\section{References}

[1] QIU Y, WU X. Design and Implementation of Web-Based Network Teaching Platform[J]. Computer Knowledge and Technology, 2009, 33: 122.

[2] Chodorow S. Educators must take the electronic revolution seriously[J]. Academic Medicine, 1996, 71(3): 221-6.

[3] Shetzer H, Warschauer M. An electronic literacy approach to network-based language teaching[J]. Network-based language teaching: Concepts and practice, 2000, 3(5): 171-185.

[4] Weining W. The Status and Developing Strategy of Network Teaching Platform in Universities [J]. Value Engineering, 2010, 31: 171.

[5] Chen X Q, Wen-Hui D I, Sun D. Application of Java web based on SSH and AJAX[J]. Computer Engineering \& Design, 2009, 30(10):2590-2589.

[6] Johnson R. J2EE development frameworks[J]. Computer, 2005, 38(1): 107-110.

[7] Qiuhui H E C Y U. Study on MVC Model2 and Struts Framework[J]. Computer Engineering, 2002, 6: 109.

[8] O'Neil E J. Object/relational mapping 2008: hibernate and the entity data model (edm)[C]//Proceedings of the 2008 ACM SIGMOD international conference on Management of data. ACM, 2008: 1351-1356.

[9] Ghanem T M, Aref W G. Databases deepen the web[J]. Computer, 2004, 37(1): 116-117.

[10] Pletch A, Agajanian A. A software engineering project that looks like the real world[J]. Journal of Computing Sciences in Colleges, 2007, 22(6): 92-99. 